\title{
Blood Coagulation Factor Xla Binds Specifically to a Site on Activated Human Platelets Distinct from That for Factor XI
}

\author{
Dipali Sinha, Frances S. Seaman, Alice Koshy, \\ Linda C. Knight, and Peter N. Walsh \\ Thrombosis Research Center, Section of Hematology/Oncology, \\ Department of Medicine, Temple University School of Medicine, \\ Philadelphia, Pennsylvania 19140
}

bstract. Binding of ${ }^{125} \mathrm{I}$-Factor XIa to platelets required the presence of high molecular weight kininogen, was enhanced when platelets were stimulated with thrombin, and reached a plateau after 4-6 min of incubation at $37^{\circ} \mathrm{C}$. Factor XIa binding was specific: 50 to 100-fold molar excesses of unlabeled Factor XIa prevented binding, whereas Factor XI, prekallikrein, Factor $\mathrm{XIIa}$, and prothrombin did not. When washed erythrocytes, added at concentrations calculated to provide an equivalent surface area to platelets, were incubated with Factor XIa, only a low level of nonspecific, nonsaturable binding was detected. Factor XIa binding to platelets was partially reversible and was saturable at concentrations of added Factor XIa of 0.2-0.4 $\mu \mathrm{g} / \mathrm{ml}(1.25-2.5 \mu \mathrm{M})$. The number of Factor XIa binding sites on activated platelets was estimated to be 225 per platelet (range, 110450). We conclude that specific, high affinity, saturable binding sites for Factor XIa are present on activated platelets, are distinct from those previously demonstrated for Factor XI, and require the presence of high molecular weight kininogen.

\section{Introduction}

Activated platelets can interact specifically with human blood coagulation Factor XI in the presence of high molecular weight

This paper was previously reported in abstract form (Sinha, D., F. S. Seaman, A. Koshy, and P. N. Walsh. 1983. Binding of blood coagulation Factor XIa to human platelets. Thromb. Haemostasis. 50:251).

Please address all reprint requests to Dr. Peter N. Walsh, Thrombosis Research Center, Temple University School of Medicine.

Received for publication 23 December 1983 and in revised form 14 February 1984.

J. Clin Invest.

(c) The American Society for Clinical Investigation, Inc.

0021-9738/84/06/1550/07 \$1.00

Volume 73, June 1984, 1550-1556 kininogen (1). One of the inferred, although not rigorously proven, consequences of this high-affinity, specific, saturable binding of Factor XI to platelets is the proteolytic activation of Factor XI on the platelet surface in the presence of kallikrein by both Factor XII-dependent and Factor XII-independent mechanisms (2). It was also demonstrated that the proteolytic cleavage products of Factor XI, i.e., Factor XIa, were associated with the platelet pellet. Furthermore, when purified Factor XI or Factor XIa was incubated with washed platelets or with platelet membranes, a 5- to 50-fold potentiation of coagulant activity was observed $(2,3)$. This enhanced activity, not seen with phospholipids, was sedimentable and saturable and was inhibited by incubation with anti-Factor XI antibody or with phospholipase C (3).

These observations led us to study the requirements, specificity, and characteristics of the interaction of Factor XIa with human platelets. Our results demonstrate specific, high affinity binding of Factor XIa to a site on activated platelets distinct from that for the zymogen, Factor XI.

\section{Methods}

All chemicals were the best grade commercially available. Methyl silicon oil (1.0 DC200) and Hi Phenyl silicon oil (125 DC550) were obtained from William F. Nye, Inc. (Fairhaven, MA). Crystallized bovine serum albumin (BSA) (Sigma Chemical Co., St. Louis, MO) was used in buffers. Benzamidine hydrochloride, soybean trypsin inhibitor, sodium heparin, and cephalin (rabbit brain extract) were purchased from Sigma Chemical Co. Diisopropylfluorophosphate was obtained from Aldrich Chemical Co., Inc., (Milwaukee, WI). Carrier-free Na ${ }^{125} \mathrm{I}$, ${ }^{125} \mathrm{I}$-labeled Bolton and Hunter reagent, and ${ }^{51} \mathrm{Cr}$-labeled sodium chromate were obtained from New England Nuclear (Boston, MA). Plasma deficient in Factor XI was obtained from George King Biomedical (Overland Park, KA). Acrylamide, sodium dodecyl sulfate (SDS), $N, N^{\prime}$-methylene-bis-acrylamide, $N, N, N^{\prime}, N^{\prime}$-tetramethylethylenediamine, and cyanogen bromide-activated Sepharose were purchased from Bio-Rad Laboratories (Richmond, CA). Ultro Hepes was from Calbiochem-Behring Corp. (San Diego, CA). The chromogenic substrate Pyr-Gly-Pro-Arg-paranitroanilide $2 \mathrm{HCl}$ (S-2366) was a gift from AB Kabi Peptide Research (Stockholm, Sweden).

Purification of proteins. Factor XI was purified from human plasma by a modification (4) of the method of Bouma and Griffin (5). The specific activity of the purified Factor XI was $270 \mathrm{U} / \mathrm{mg}$. High molecular 
weight kininogen ( $15 \mathrm{U} / \mathrm{mg} \mathrm{sp}$ act) was purified and converted to the kinin-free two-chain form by the method of Kerbiriou and Griffin (6). Prekallikrein ( $133 \mathrm{U} / \mathrm{mg} \mathrm{sp}$ act) was isolated by the method of Kerbiriou et al. (7). Kallikrein was prepared from prekallikrein as reported by Bouma et al. (8). Prothrombin was purified as previously described (4). Human alpha-thrombin was a gift from Dr. J. W. Fenton II, New York State Department of Health, and bovine Factor XIIa was kindly provided by Dr. E. P. Kirby of the Thrombosis Research Center of the Temple University School of Medicine. All proteins were $>\mathbf{9 8 \%}$ pure as judged by polyacrylamide slab gel electrophoresis in SDS.

Activation of Factor XI. Purified Factor XI was activated by incubation with bovine Factor XIIa, as previously described (4). The appearance of maximal coagulant activity occurred at $2 \mathrm{~h}$ of incubation, at which time $>95 \%$ of the protein was present in cleavage products of molecular weight 48,000 and 32,000 (see Fig. 1).

Functional assays of coagulation proteins. Factors XI, prekallikrein, and high molecular weight kininogen were assayed using minor modifications of the kaolin-activated partial thromboplastin time (4) with appropriate congenitally deficient substrate plasmas. Factor XIa activity was estimated by a similar assay carried out in siliconized glass tubes without the addition of kaolin (4).

Factor XIa was also assayed for amidolytic activity using the chromogenic substrate, Pyr-Glu-Pro-Arg-p-nitroanilide (S-2366), as previously described (9), and for antigenic activity by radioimmunoassay using monospecific rabbit antihuman Factor XI, as previously described (4, 9). The radioimmunoassay did not distinguish between Factor XI and Factor XIa and could be used to measure either protein. By comparing the results of the amidolytic assay of purified Factor XIa $(127 \mathrm{U} / \mathrm{ml})$ with those of the Factor XI coagulation assays for purified Factor XIa $(135 \mathrm{U} / \mathrm{ml})$ and with the radioimmunoassay for Factor XI $(750 \mu \mathrm{g} / \mathrm{ml})$, we could determine a specific activity for our Factor XIa preparation of $180 \mathrm{U} / \mathrm{mg}$ protein.

Preparation of ${ }^{125}$ I-labeled Factor XIa. For binding studies, ${ }^{125} \mathrm{I}$ labeled Factor XI was prepared both by the procedure of Bolton and Hunter (10) and by the Iodogen method (11). Most of free ${ }^{125}$ I was then separated by passage through a 1-ml G-25 column (12). The labeled protein was further dialyzed in the presence of ovalbumin $(1 \mathrm{mg} / \mathrm{ml})$. ${ }^{125}$ I-Factor XIa was prepared from the zymogen using Factor XIIa as described above. The specific radioactivity of the protein obtained by the Iodogen method was $\sim 1.1 \times 10^{6} \mathrm{cpm} / \mu \mathrm{g}$, compared with 0.5 $\times 10^{6} \mathrm{cpm} / \mu \mathrm{g}$, obtained by the Bolton and Hunter procedure. More than $85 \%$ of the clotting activity of Factor XIa was retained after radiolabeling by either method. In binding experiments both proteins gave identical results.

Protein analysis. Protein assays were performed according to the method of Lowry et al. (13). Polyacrylamide slab gel electrophoresis in SDS was carried out according to the procedure of Laemmli (14).

Preparation of platelet and erythrocyte suspensions. Platelet-rich plasma was obtained from citrated human blood and gel filtered on a Sepharose 2B column equilibrated in calcium-free Hepes Tyrode's buffer, pH 7.3, containing BSA, $1 \mathrm{mg} / \mathrm{ml}$ (15). Platelets were counted electronically (Coulter Electronics, Inc., Hialeah, FL). A 1-ml aliquot of the pellet, after removal of the platelet-rich plasma and the buffy coat, was used to make red cell suspensions. To remove plasma and contaminating platelets from the red cell suspension, it was washed five times with Hanks' balanced salt solution by centrifugation at $150 \mathrm{~g}$ for $10 \mathrm{~min}$ and finally suspended in Hepes Tyrode's buffer, pH 7.4, containing BSA (1 $\mathrm{mg} / \mathrm{ml}$ ). The red cells were counted microscopically and adjusted to concentrations such that total surface area of the cells per milliliter in the red cell and platelet suspensions were equivalent. Surface area for erythrocytes was assumed to be $145 \mu \mathrm{m}^{2}$ (16); for platelets, surface area was calculated to be $18 \mu \mathrm{m}^{2}$, assuming spherical shape and mean platelet volume of $7.5 \mathrm{fl}$, as determined by electronic sizing (Coulter Electronics, Inc.) in our laboratory.

Binding experiments. In a typical binding experiment, $100 \mu \mathrm{l}$ of gelfiltered platelets $\left(2-4 \times 10^{8} / \mathrm{ml}\right)$ in calcium-free Hepes Tyrode's buffer, pH 7.4, were incubated at $37^{\circ} \mathrm{C}$ in a $1.5 \mathrm{ml}$ polypropylene centrifuge tube (Sarstedt, Inc., Princeton, NJ) with high molecular weight kininogen, thrombin, and radiolabeled Factor XIa in a total volume of $115 \mu \mathrm{l}$. In time course experiments, after incubation of appropriately expanded volumes for a specified time, $100-\mu$ l aliquots were removed and centrifuged in a microfuge (model B; Beckman Instruments, Inc., Cedar Grove, NJ) through a mixture of silicon oils (5 vol DC550:1 vol DC200) in microsediment tubes with narrow bore extended tips (Sarstedt, Inc., Princeton, NJ). The tips containing the sediments were amputated with wire cutters and the supernatants and sediments were counted separately in a gamma counter (model CG 4000; Intertechnique, Plaisir, France). In concentration dependency determinations, incubations were done for $5 \mathrm{~min}$, before centrifugation through oil. In experiments with platelets labeled with ${ }^{51} \mathrm{Cr},>94 \%$ of the radioactivity was recovered in the pellet, thus confirming that the binding assay functioned to sediment the platelets. When platelets were incubated with ${ }^{125} \mathrm{I}$-labeled BSA to measure trapped volume, the fraction of radioactivity that appeared in the pellet was $<0.005$. When ${ }^{125}$ I-labeled Factor XIa was centrifuged over silicon oils in the absence of platelets, the fraction of radioactivity that appeared in the pellet was $<0.001$. Therefore, the procedure used was validated as a method to separate platelets from unbound ligand.

\section{Results}

Results of polyacrylamide gel electrophoresis in SDS of purified Factor XI and Factor XIa, under both nonreducing and reducing conditions, are shown in Fig. 1. Radiolabeling did not affect the electrophoretic behavior of either molecule. Both ${ }^{125} \mathrm{I}$-labeled and unlabeled Factor XI and Factor XIa migrated as 160,000mol-wt proteins under nonreducing conditions, whereas under reducing conditions Factor $\mathrm{XI}$ appeared as a single band at 80,000 mol wt and Factor XIa appeared as two bands, one at $48,000 \mathrm{~mol} \mathrm{wt}$ the other at $32,000 \mathrm{~mol} \mathrm{wt}$.

The time course of binding of ${ }^{125}$ I-Factor XIa to platelets is shown in Fig. 2. When neither thrombin nor high molecular weight kininogen was present in the incubation mixture, $<0.5$ ng of Factor XIa was bound per $10^{8}$ platelets. In contrast, when both thrombin and high molecular weight kininogen were present, Factor XIa binding progressively increased to a maximum, at 4-6 min, of $\sim 3.5 \mathrm{ng} / 10^{8}$ platelets. In the presence of thrombin alone, very little if any binding was observed, whereas in the presence of high molecular weight kininogen alone, $10-60 \%$ of maximum binding was observed in different experiments, probably reflecting partial activation of platelets during gel filtration. When ADP $(10 \mu \mathrm{M})$ replaced thrombin in similar experiments, Factor XIa binding was seen to occur to a lesser extent over a slower time course (data not shown). Identical results were obtained when binding experiments were carried out with $\mathrm{CaCl}_{2}$ added at concentrations of $50 \mu \mathrm{M}$ to $5 \mathrm{mM}$, or with EDTA at concentrations of $25-200 \mu \mathrm{M}$. 


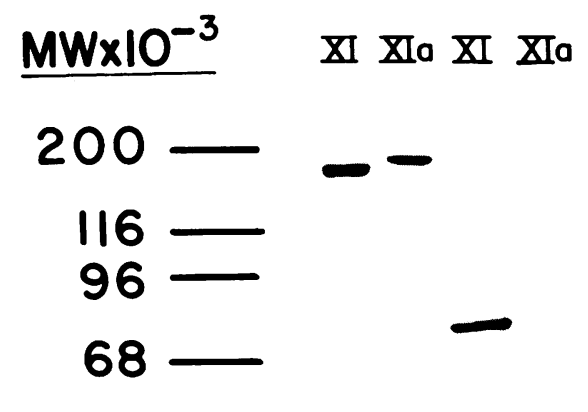

45

31

UNREDUCED REDUCED

Figure 1. Polyacrylamide (7.5\%) gel electrophoresis in SDS of Factor XI and Factor XIa. A total of 4-5 $\mu \mathrm{g}$ of Factor XI or Factor XIa, prepared as described in Methods, was applied to each lane in the presence or absence of $\beta$-mercaptoethanol as a reducing agent. $\mathrm{MW}$, molecular weight.

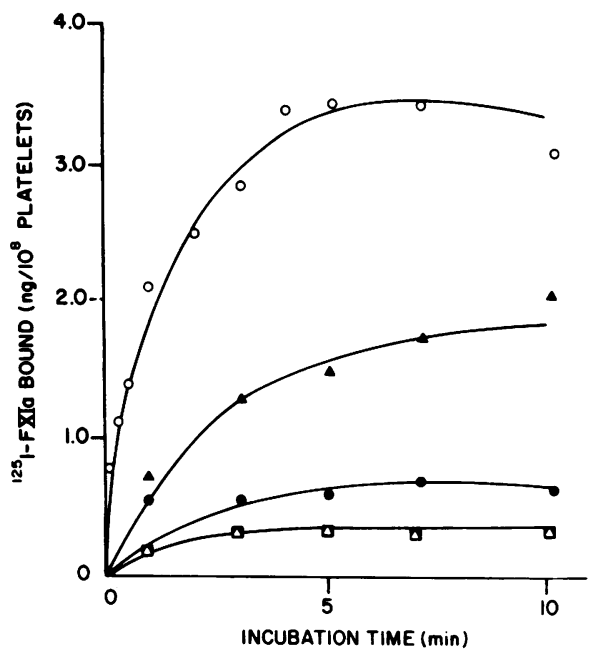

Figure 2. Time course of binding of ${ }^{125} \mathrm{I}$-Factor $\mathrm{XI}$ to platelets and erythrocytes. Platelets $\left(2.04 \times 10^{8} / \mathrm{ml}\right)$ and Factor XIa $(0.6 \mu \mathrm{g} / \mathrm{ml})$ were incubated at $37^{\circ} \mathrm{C}$ with thrombin $(0.25 \mathrm{U} / \mathrm{ml})$ and high molecular weight kininogen $(12.5 \mu \mathrm{g} / \mathrm{ml})(0)$; with thrombin alone $(\bullet)$; with high molecular weight kininogen alone ( $\Delta)$; or with neither protein $(\triangle)$; and binding was determined as described in Methods. Alternatively, washed erythrocytes $\left(0.255 \times 10^{8} / \mathrm{ml} ; \square\right)$ were incubated with ${ }^{125} \mathrm{I}$-Factor XIa, thrombin, and high molecular weight kininogen as above, and binding was determined at the designated time points.
To determine whether the binding characteristics of ${ }^{125} \mathrm{I}$ labeled and unlabeled Factor XIa were comparable, gel-filtered platelets were incubated with thrombin and high molecular weight kininogen in the presence of mixtures of ${ }^{125}$ I-labeled and unlabeled Factor XIa. When the final concentration of Factor XIa remained constant but the proportion of unlabeled to radiolabeled ligand was varied, a linear relationship was observed between the percentage of ${ }^{125} \mathrm{I}$-labeled Factor XIa in the mixtures and the amount bound (Fig. 3). This indicated that the affinities of radiolabeled and unlabeled Factor XIa were comparable.

The effect of high molecular weight kininogen concentration on the binding of Factor XIa to platelets in the presence of thrombin is shown in fig. 4. A sigmoid curve was consistently noted in this and similar experiments, with saturation occurring at concentrations of $12-30 \mu \mathrm{g} / \mathrm{ml}$. At concentrations of high molecular weight kininogen of 50 and $100 \mu \mathrm{g} / \mathrm{ml}$, binding of ${ }^{125} \mathrm{I}$-Factor XIa was diminished so that $62 \%$ of maximal binding was observed at $100 \mu \mathrm{g} / \mathrm{ml}$ of high molecular weight kininogen.

The effect of various concentrations of thrombin on the binding of Factor XIa to platelets was examined in the presence of high molecular weight kininogen (Fig. 5). No appreciable effect of thrombin was observed at concentrations of $0.05 \mathrm{U} /$ $\mathrm{ml}$ or less, whereas a plateau was observed at concentrations ranging between 0.1 and $0.3 \mathrm{U} / \mathrm{ml}$; at higher concentrations of thrombin we observed progressively diminished binding.

To determine the specificity of binding of Factor XIa to platelets, we added a variety of proteins, in 50- to 100-fold molar excess compared with radiolabeled Factor XIa, to platelet suspensions in the presence of thrombin and high molecular weight

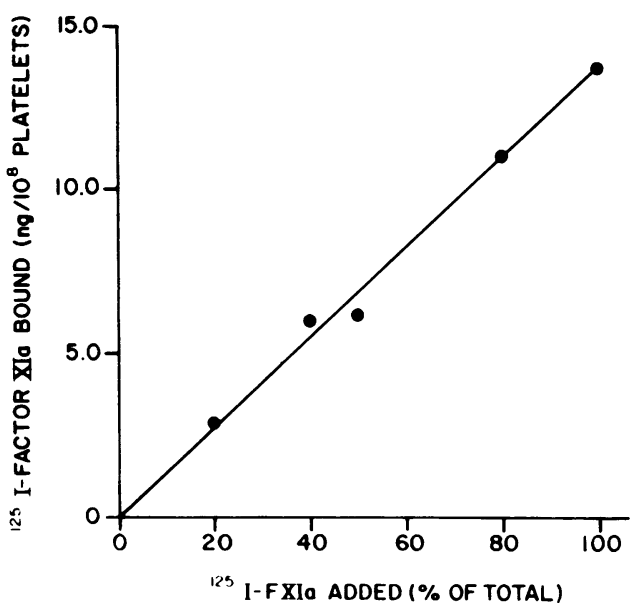

Figure 3. Relative binding of ${ }^{125} \mathrm{I}$-labeled and unlabeled Factor XIa to activated platelets in the presence of high molecular weight kininogen. Gel-filtered platelets $\left(2.45 \times 10^{8} / \mathrm{ml}\right)$ were incubated for $5 \mathrm{~min}$ at $37^{\circ} \mathrm{C}$ with thrombin $(0.1 \mathrm{U} / \mathrm{ml})$ and high molecular weight kininogen $(12 \mu \mathrm{g} / \mathrm{ml})$ in the presence of various proportions of ${ }^{125} \mathrm{I}$-labeled and unlabeled Factor XIa, keeping the total concentration of Factor Xla constant at $0.10 \mu \mathrm{g} / \mathrm{ml}$. Binding was determined as detailed in Methods, and binding of ${ }^{125}$-labeled Factor XIa was plotted as a function of the fraction of ${ }^{125} \mathrm{I}$-labeled Factor XIa added. 


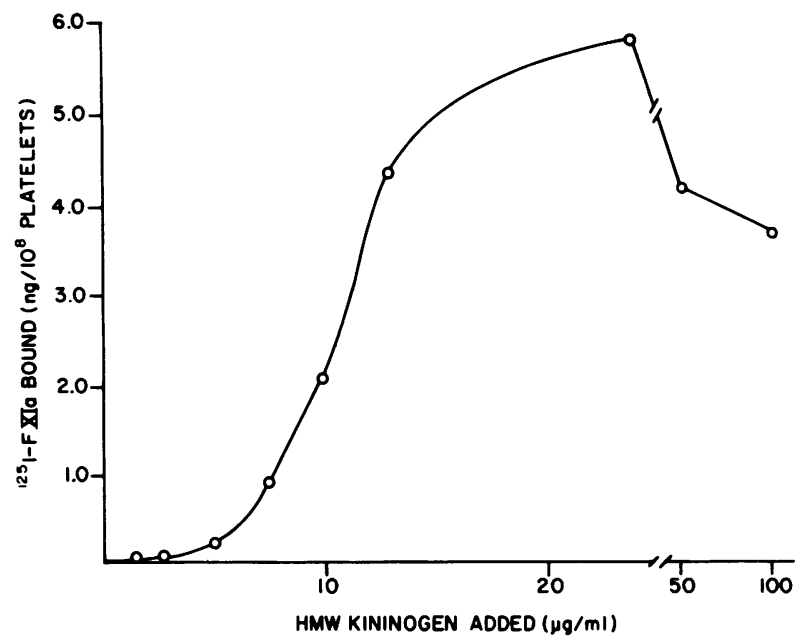

Figure 4. The effect of high molecular weight (HMW) kininogen concentration on the binding of Factor XIa to activated platelets. Gelfiltered platelets $\left(2.25 \times 10^{8} / \mathrm{ml}\right)$ were incubated for $5 \mathrm{~min}$ at $37^{\circ} \mathrm{C}$ with ${ }^{125} \mathrm{I}$-labeled Factor XIa $(0.6 \mu \mathrm{g} / \mathrm{ml})$ and thrombin $(0.25 \mathrm{U} / \mathrm{ml})$ in the presence of various concentrations of high molecular weight kininogen. Binding was determined as indicated in Methods.

kininogen (Table I). When a 50-fold molar excess of cold Factor XIa was added to the incubation mixture that contained 0.45 $\mu \mathrm{g} / \mathrm{ml}$ of radiolabeled Factor XIa, only $11 \%$ of control binding was observed, indicating that $\sim 89 \%$ was prevented. In contrast, when zymogen, Factor XI, was added at the same concentration as cold Factor XIa, virtually no competition was observed. Similar results were obtained when Factor XIIa, prekallikrein, and prothrombin were added in a 50 - to 100 -fold molar excess.

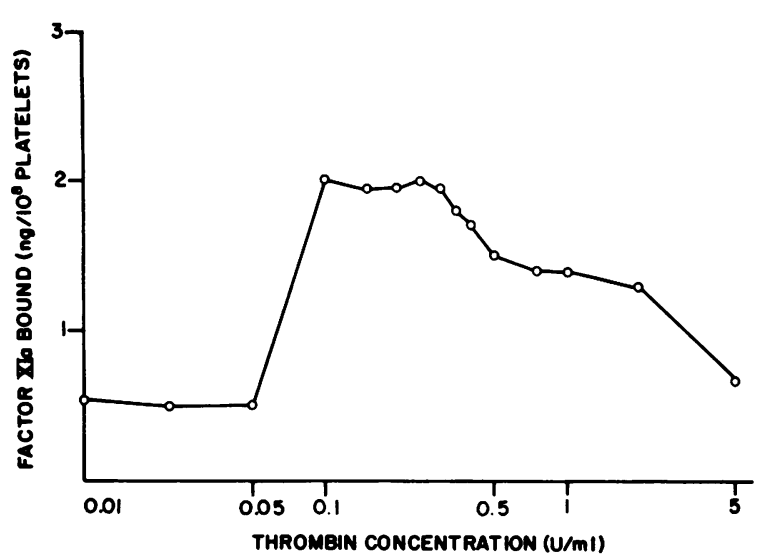

Figure 5. The effect of thrombin concentration on binding of Factor XIa to platelets in the presence of high molecular weight kininogen. Gel-filtered platelets $\left(2.68 \times 10^{8} / \mathrm{ml}\right)$ were incubated with ${ }^{125} \mathrm{I}$-labeled Factor XIa $(0.56 \mu \mathrm{g} / \mathrm{ml})$ in the presence of high molecular weight kininogen $(12.5 \mu \mathrm{g} / \mathrm{ml})$ and thrombin at the concentration indicated. Binding was determined as indicated in Methods.
Table I. Specificity of Binding ${ }^{125}$ I-Factor XIa to Platelets

\begin{tabular}{lll}
\hline $\begin{array}{l}\text { Protein added in 50- to } \\
\text { 100-fold molar excess }\end{array}$ & $\begin{array}{l}\text { Amount of } \\
\text { 125I-Factor } \\
\text { XI bound }\end{array}$ & $\begin{array}{l}\text { Factor XIa bound } \\
\text { as a percentage of } \\
\text { control }\end{array}$ \\
\hline & $n g / 10^{8}$ platelets \\
None & 3.31 & 100 \\
Factor XIa $(22.5 \mu \mathrm{g} / \mathrm{ml})$ & 0.37 & 11 \\
Factor XI $(22.5 \mu \mathrm{g} / \mathrm{ml})$ & 3.11 & 94 \\
Factor XIIa $(11.3 \mu \mathrm{g} / \mathrm{ml})$ & 3.31 & 100 \\
Prekallikrein $(22.5 \mu \mathrm{g} / \mathrm{ml})$ & 3.68 & 111 \\
Prothrombin $(20.2 \mu \mathrm{g} / \mathrm{ml})$ & 2.37 & 72 \\
\hline
\end{tabular}

Gel-filtered platelets $\left(2.27 \times 10^{8} / \mathrm{ml}\right)$ in Hepes Tyrode's buffer, $\mathrm{pH}$ 7.4 , were incubated at $37^{\circ} \mathrm{C}$ with ${ }^{125} \mathrm{I}$-Factor XIa $(0.45 \mu \mathrm{g} / \mathrm{ml})$ in the presence of thrombin $(0.25 \mathrm{U} / \mathrm{ml})$, high molecular weight kininogen $(12.5 \mu \mathrm{g} / \mathrm{ml})$, and the purified proteins indicated. After $5 \mathrm{~min}$, samples were centrifuged through silicon oils for measurement of bound and free ligand as indicated in Methods.

These results indicate that the binding of Factor XIa to platelets is specific and that the binding site is distinct from that for Factor XI.

To examine further the specificity of this interaction, the characteristics of radiolabeled Factor XIa binding to red cells (added at a concentration calculated to provide a surface area equivalent to that of platelets) were determined in the presence of thrombin and high molecular weight kininogen (Fig. 1). The time course of binding to platelets is shown in the figure; the low level of binding to red cells was similar to nonspecific binding to platelets. Fig. 6 demonstrates saturable binding of Factor XIa to platelets at various ligand concentrations, whereas nonsaturable, nonspecific binding to red cells was observed.

To study the reversibility of binding, gel-filtered platelets were incubated with radiolabeled Factor XIa in the presence of high molecular weight kininogen and thrombin, and after a plateau was achieved at 4 min of incubation, a 50-fold molar excess of cold Factor XIa was added to the incubation mixture to determine whether reversal of binding would occur (Fig. 7). Rapid dissociation of bound ligand was observed, and $10 \mathrm{~min}$ after addition of cold Factor XIa, 35-40\% of the bound ligand was displaced. No further reversal of binding was observed when incubations were carried out to $30 \mathrm{~min}$.

To determine whether the binding of Factor XIa to platelets was saturable and to estimate the number and affinity of binding sites for Factor XIa, Factor XIa binding to thrombin activated platelets in the presence of high molecular weight kininogen was measured as a function of total concentration of Factor XIa (Fig. 6). Nonspecific binding was measured in the presence of excess cold Factor XIa, and similar results were obtained in the absence of both thrombin and high molecular weight kininogen, or when erythrocytes (added at a concentration calculated to provide equivalent surface area) replaced platelets in 


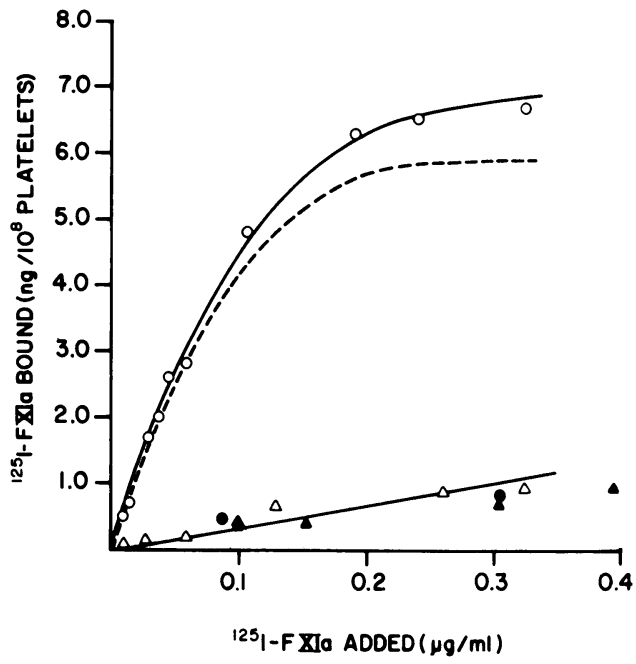

Figure 6. Binding of ${ }^{125} \mathrm{I}$-Factor XI to platelets $\left(2.2 \times 10^{8} / \mathrm{ml}\right)$ as a function of Factor XIa concentration. Incubations were carried out and binding was determined as in Fig. 2 in the presence of $0.1 \mathrm{U} / \mathrm{ml}$ thrombin and $12 \mu \mathrm{g} / \mathrm{ml}$ high molecular weight kininogen (o), or in the absence of thrombin and high molecular weight kininogen $(\Delta)$. Nonspecific binding was measured in the presence of thrombin, high molecular weight kininogen, and $14 \mu \mathrm{g} / \mathrm{ml}$ unlabeled Factor XIa (0). Specific binding is indicated by the dashed curve. Alternatively washed erythrocytes $\left(0.25 \times 10^{8} / \mathrm{ml}\right)$ were substituted for platelets and incubated with thrombin and high molecular weight kininogen, and binding was determined as above ( $(\mathbf{)}$.

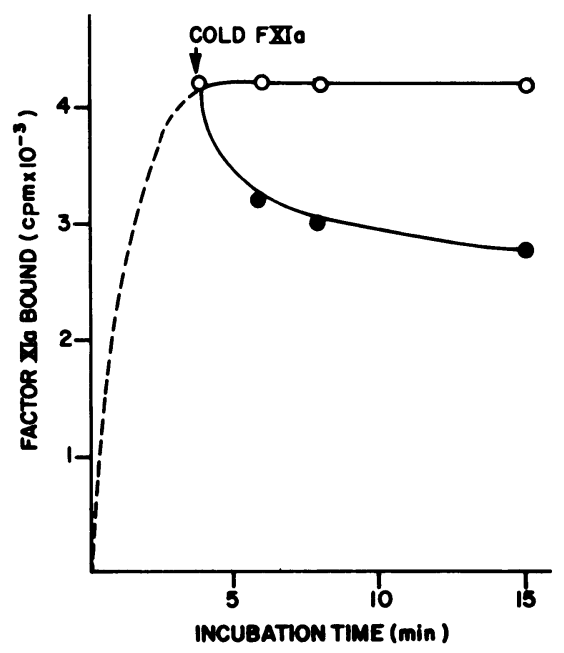

Figure 7. Reversibility of Factor XIa binding to activated platelets in the presence of high molecular weight kininogen. Gel-filtered platelets $\left(3 \times 10^{8} / \mathrm{ml}\right)$ were incubated for 4 min with ${ }^{125} \mathrm{I}$-labeled Factor XIa $(0.375 \mu \mathrm{g} / \mathrm{ml})$ in the presence of high molecular weight kininogen $(12.5 \mu \mathrm{g} / \mathrm{ml})$ and thrombin $(0.2 \mathrm{U} / \mathrm{ml})$. At $4 \mathrm{~min}, 18.8 \mu \mathrm{g} / \mathrm{ml}$ of unlabeled Factor XIa ( $\bullet$ ) or of buffer $(0)$ was added. Binding was determined at the indicated time points as indicated in Methods. incubation mixtures that contained both thrombin and high molecular weight kininogen. Specific binding (defined as the difference between total binding and nonspecific binding) is indicated by the dashed curve. Since $60 \%$ of Factor XIa binding is irreversible, we did not analyze our binding data assuming equilibrium between bound and free ligand. Alternatively, we have estimated, from six experiments similar to that illustrated in Fig. 6, the concentration of added Factor XIa at which all sites are occupied to be $0.2-0.4 \mu \mathrm{g} / \mathrm{ml}(1.25-2.5 \mathrm{nM})$. Our calculations from Fig. 6 and five similar experiments suggest that the amount of Factor XIa bound is $\sim 6 \mathrm{ng} / 10^{8}$ platelets (range 3.0-11.5) and that the total number of specific binding sites on activated platelets is therefore $\sim 225$ per platelet (range $110-$ 450). When the data presented in Fig. 6 were plotted as Factor XIa bound vs. the logarithm of free Factor XIa as suggested by Klotz (17), a sigmoid curve resulted, indicating that at the concentrations of ligand added, saturation of binding sites was approached.

To characterize the bound Factor XIa, platelets were incubated with high molecular weight kininogen and thrombin and centrifuged through $20 \%$ sucrose to isolate bound ligand. When the experiment was done without added platelets, the fraction of radioactivity recovered in the pellet was $<0.001$. Platelet pellets were solubilized in $2 \%$ SDS and were analyzed both by $7.5 \%$ polyacrylamide gel electrophoresis in the presence of SDS and by later radioautography. More than $95 \%$ of the ${ }^{125}$ I was solubilized and applied to the gel. The bound radioligand migrated as a 160,000 -mol-wt protein on nonreduced gels and was indistinguishable from added Factor XI (data not shown). On reduced gels the bound Factor XIa migrated as two polypeptides of 48,000 and $32,000 \mathrm{~mol}$ wt and was again indistinguishable from free Factor XIa (Fig. 8). This experiment provides

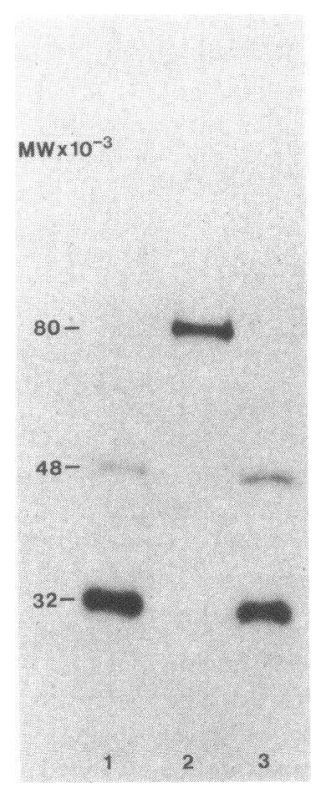

Figure 8. Autoradiograms of reduced $7.5 \%$ polyacrylamide gel electrophoretograms of ${ }^{125}$ I-labeled Factor XIa (lane 1), ${ }^{125}$ I-labeled Factor XI (lane 2), and bound ${ }^{125}$ I-labeled Factor XIa (lane 3). Gel-filtered platelets $\left(4.5 \times 10^{8} / \mathrm{ml}\right)$ were incubated for $8 \mathrm{~min}$ at $37^{\circ} \mathrm{C}$ with ${ }^{125} \mathrm{I}$-labeled Factor XIa $(2.5 \mu \mathrm{g} / \mathrm{ml})$, high molecular weight kininogen $(20 \mu \mathrm{g} / \mathrm{ml})$, and thrombin $(0.1 \mathrm{U} / \mathrm{ml})$. After centrifugation through $20 \%$ sucrose, the platelet pellet was solubilized in $2.0 \%$ SDS containing 1 $\mathrm{mM}$ diisopropylfluorophosphate, $1 \mathrm{mM}$ benzamidine, and $1 \mathrm{mM}$ EDTA, and applied to the gel. MW, molecular weight. 
no evidence for the formation of high molecular weight covalent complexes or for proteolytic degradation of Factor XIa by platelets.

\section{Discussion}

The present studies support the conclusion that the enzyme, Factor XIa, interacts specifically with a platelet membrane binding site that is not present on erythrocytes and that is distinct from that previously demonstrated for zymogen, Factor XI (1). Binding of Factor XIa to platelets requires the presence of the cofactor with which Factor XI circulates in plasma, high molecular weight kininogen (18), is enhanced by platelet activation with thrombin, and is unaffected by the addition of $\mathrm{CaCl}_{2}$ at concentrations of $50 \mu \mathrm{M}$ to $5 \mathrm{mM}$ or of EDTA at concentrations of 25-200 $\mu \mathrm{M}$.

As a part of our attempts to define the mechanism by which high molecular weight kininogen promotes the binding to platelets of both Factor XI and Factor XIa, we have carried out binding studies with radiolabeled high molecular weight kininogen (not reported here). A possible mechanism is that Factor XIa forms a noncovalent complex with high molecular weight kininogen in plasma $(18,19)$, and that the two proteins bind coordinately to platelets as a complex, such as has been demonstrated for Factor Xa and Factor Va (20). However, we have been able to demonstrate only a low level of nonspecific, nonsaturable association of high molecular weight kininogen with platelets in the presence of Factor XIa under the conditions employed here. In the presence of $\mathrm{ZnCl}_{2}$, specific, saturable binding of both Factor $\mathrm{XI}$ and high molecular weight kininogen to activated platelets can be demonstrated (21). In the absence of $\mathrm{ZnCl}_{2}$, binding of Factor XIa, but of neither high molecular weight kininogen nor Factor XI, can be demonstrated. We interpret this fact, and the observation reported here that Factor XI fails to compete with Factor XIa for binding to platelets, as evidence that the binding sites on activated platelets for these two ligands are distinct. Our data further suggest that the interaction of Factor XIa and high molecular weight kininogen in a soluble-phase, noncovalent complex (18) is required for Factor XIa binding to activated platelets. Furthermore, the concentration range $(12-30 \mu \mathrm{g} / \mathrm{ml})$ of high molecular weight kininogen that affects the extent of Factor XIa binding (Fig. 4) is lower than its normal plasma concentration $(80 \mu \mathrm{g} / \mathrm{ml})$, which could therefore be expected to regulate the binding of Factor XIa to platelets. However, further studies will be required to define the exact mechanism by which high molecular weight kininogen promotes Factor XIa binding and to identify the nature of the binding site on activated platelets.

Schmaier et al. (22) have recently presented evidence that high molecular weight kininogen is present in platelets and can be secreted from platelets exposed to various agonists. The amount of high molecular weight kininogen present in platelets is $\sim 60 \mathrm{ng} / 10^{8}$ platelets, which comprises $\sim 0.23 \%$ of the plasma level of $80 \mu \mathrm{g} / \mathrm{ml}$, assuming a platelet concentration of $3 \times 10^{8}$ platelets/ml (22). Since the amount of high molecular weight kininogen required for half-maximal Factor XIa binding in our experiments is $10-15 \mu \mathrm{g} / \mathrm{ml}$, it is clear that the amount of this protein released from platelets would not suffice. However, the local concentration of high molecular weight kininogen on the platelet surface during secretion has not been determined. Additional work will be required to ascertain the possible role of platelet high molecular weight kininogen in Factor XIa binding.

The binding of Factor XIa to platelets is rapid, reaching a plateau in 4-6 min, and is partially reversible thereafter, with $\sim 60-65 \%$ remaining bound to platelets after a 10 -min incubation with a 50-fold excess of unlabeled ligand. Derivation of the number of binding sites and the affinity of ligand-receptor interaction by Scatchard analysis is based on the assumption that the interaction between ligand and receptor is reversible and that equilibrium between free and bound ligand can be demonstrated (23). As an alternative to such an analysis, we have estimated the concentration of added Factor XIa at which saturation of platelet sites appears to occur in a direct plot of bound vs. free ligand (Fig. 6). The impression that we had approached saturation of binding sites was confirmed by the method of Klotz (17). In a total of six similar experiments, the Factor XIa concentration at which all sites are occupied was estimated as $0.2-0.4 \mu \mathrm{g} / \mathrm{ml}(1.25-2.5 \mathrm{nM})$. When the data were plotted according to the method of Scatchard (23), a dissociation constant of $3.24 \mathrm{nM}$ was calculated for the data shown in Fig. 6 . Thus, since the concentration of Factor XI in human plasma is $25-38 \mathrm{nM}(5,24)$, if $5-10 \%$ of the Factor XI were converted to Factor XIa, all the sites on activated platelets would be occupied. Our calculations, based on direct plots of data as shown in Fig. 6, suggest that the number of specific binding sites on activated platelets is $\sim 6 \mathrm{ng} / 10^{8}$ platelets (range $3.0-11.5$ ). When the number of binding sites is calculated by Scatchard analysis for the data in Fig. 6, the result is $8.25 \mathrm{ng} / 10^{8}$ platelets, compared with $6.0 \mathrm{ng} / 10^{8}$ platelets by direct estimate. Therefore, the total number of specific binding sites on activated platelets is $\sim 225$ per platelet (range 110-450).

Characterization of bound ${ }^{125}$ I-labeled Factor XIa by polyacrylamide gel electrophoresis in SDS and by subsequent autoradiography (Fig. 8) provides evidence that the ligand bound to platelets was Factor XIa and not a contaminant. This and four similar experiments provide no evidence for the formation of high molecular weight covalent complexes or for proteolytic degradation of bound Factor XIa by platelets, since bound Factor XIa migrates on both reduced and nonreduced gels, identically to unbound Factor XIa.

Previous studies indicate that platelets can promote the proteolytic activation of Factor XII (2), Factor XI (2), Factor X $(25)$, prothrombin $(20,26)$, and possibly also Factor IX $(2,3)$. Furthermore, the kinetics of the Factor XIa catalyzed activation of Factor IX suggest that this may be a physiologically relevant reaction (4). Therefore, it will be particularly important to define the physiological consequences of Factor IXa binding to platelets by direct studies of Factor IX activation. 


\section{Acknowledgments}

The authors are grateful to Monica Kollman for her assistance in radiolabeling proteins, to Dr. Edward P. Kirby and Patrick McDevitt for their gift of bovine factor XIIa, and to Patricia Pileggi for her typing of the manuscript.

This work was supported by National Institutes of Health grants HL25661 and HL14217, by grant CTR 1389 from the Council for Tobacco Research Inc., and by a grant from the American Heart Association Pennsylvania Affiliate.

\section{References}

1. Greengard, J. S., P. N. Walsh, and J. H. Griffin. 1981. Binding of factor XI to human platelets. Blood. 58:688. (Abstr.)

2. Walsh, P. N., and J. H. Griffin. 1981. Contributions of human platelets to the proteolytic activation of blood coagulation factors XII and XI. Blood. 57:106-118.

3. Walsh, P. N., G. P. Tuszynski, S. J. Bevacqua, and J. H. Griffin. 1980. Platelets potentiate coagulant activity of contact factors. Clin. Res. 28:498A. (Abstr.)

4. Walsh, P. N., H. Bradford, D. Sinha, J. R. Piperno, and G. P. Tuszynski. 1984. Kinetics of the Factor XIa catalyzed activation of human blood coagulation Factor IX. J. Clin. Invest. 73:1392-1399.

5. Bouma, B. N., and J. H. Griffin. 1977. Human blood coagulation factor XI. Purification, properties, and mechanism of activation by activated factor XII. J. Biol. Chem. 252:6432-6437.

6. Kerbiriou, D. M., and J. H. Griffin. 1979. Human high molecular weight kininogen. Studies of structure-function relationships and of proteolysis of the molecule occurring during contact activation of plasma. J. Biol. Chem. 254:12020-12027.

7. Kerbiriou, D. M., B. N. Bouma, and J. H. Griffin. 1980. Immunochemical studies of human high molecular weight kininogen and of its complexes with plasma prekallikrein or kallikrein. J. Biol. Chem. 255:3952-3958.

8. Bouma, B. N., L. A. Miles, G. Beretta, and J. H. Griffin. 1980. Human plasma prekallikrein. Studies of its activation by activated factor XII and of its inactivation by diisopropylphosphofluoridate. Biochemistry. 19:1151-1160.

9. Scott, C. F., D. Sinha, F. S. Seaman, P. N. Walsh, and R. W. Colman. 1984. A new functional amidolytic assay of factor XI in human plasma: comparison with radioimmunoassay and coagulant activity. Blood. 63:42-50.

10. Bolton, A. E., and W. M. Hunter. 1973. The labeling of proteins to high specific radioactivities by conjugation to a ${ }^{125}$ I-containing acylating agent. Biochem. J. 133:529-539.
11. Fraker, P. J., and J. C. Speck. 1978. Protein and cell membrane iodinations with a sparingly soluble chloramide, 1,3,4,6-tetrachloro-3a,6adiphenylglycoluril. Biochem. Biophys. Res. Commun. 80:849-857.

12. Tuszynski, G. P., L. Knight, J. R. Piperno, and P. N. Walsh. 1980. A rapid method for removal of ${ }^{125}$ I-Iodide following iodination of protein solutions. Anal. Biochem. 106:118-122.

13. Lowry, O. H., N. J. Rosebrough, A. L. Farr, and R. J. Randall. 1951. Protein measurement with the Folin phenol reagent. J. Biol. Chem. 193:265-275.

14. Laemmli, U. K. 1970. Cleavage of structural proteins during the assembly of the head of bacteriophage $T_{4}$. Nature (Lond.). 227:680685 .

15. Timmons, S., and J. Hawiger. 1978. Separation of human platelets from plasma proteins including factor VIII $_{\text {vwf }}$ by a combined albumin gradient-gel filtration method using hepes buffer. Thromb. Res. 12:297306.

16. Altman, P. L., and D. S. Dittmer. 1971. Blood and Other Body Fluids. Federation of American Societies for Experimental Biology, Bethesda. 110.

17. Klotz, I. M. 1982. Numbers of receptor sites from Scatchard graphs: facts and fantasies. Science (Wash. DC). 217:1247-1249.

18. Thompson, R. E., R. Mandle, Jr., and A. P. Kaplan. 1977. Association of Factor XI and high molecular weight kininogen in plasma. J. Clin. Invest. 60:1376-1380.

19. Scott, C. F., M. Schapira, H. L. James, A. B. Cohen, and R. W. Colman. 1982. Interaction of Factor XIa by plasma protease inhibitors. Predominant role of $\alpha_{1}$-protease inhibitor and protective effect of high molecular weight kininogen. J. Clin. Invest. 69:844-852.

20. Tracy, P. B., M. E. Nesheim, and K. G. Mann. 1981. Coordinate binding of factor Va and factor Xa to the unstimulated platelets. J. Biol. Chem. 256:743-751.

21. Greengard, J. S., E. Ersdahl, and J. H. Griffin. 1983. Binding of purified high molecular weight kininogen, factor XI and factor XIa to washed human platelets. Blood. 62:256a. (Abstr.)

22. Schmaier, A. H., A. Zuckerberg, C. Silverman, J. Kuchibhotla, G. P. Tuszynski, and R. W. Colman. 1983. High molecular weight kininogen. A secreted platelet protein. J. Clin. Invest. 71:1477-1489.

23. Scatchard, G. 1949. The attractions of proteins for small molecules and ions. Ann. NY Acad. Sci. 51:660-672.

24. Saito, H., and G. H. Goldsmith. 1977. Plasma thromboplastin antecedent (PTA, factor XI): a specific and sensitive radioimmunoassay. Blood. 50:377-385.

25. Walsh, P. N., and R. Biggs. 1972. The role of platelets in intrinsic factor Xa formation. Brit. J. Haematol. 22:743-760.

26. Miletich, J. P., C. M. Jackson, and P. W. Majerus. 1977. Interaction of coagulation factor Xa with human platelets. Proc. Natl. Acad. Sci. USA. 74:4033-4036. 